\title{
Polymerase chain reaction (PCR) - A review with its pertinency to dentistry
}

\author{
Sumit Kumar Yadav', Achla Bharti Yadav², Neal Bharat Kedia ${ }^{3}$, Gunjan Kedia ${ }^{4}$, Kunal Kumar ${ }^{5}$ \\ ${ }^{1,2}$ Reader, ${ }^{3}$ Professor, ${ }^{4}$ Senior Lecturer, ${ }^{5}$ Senior Resident, Dept. of Oral Pathology, ${ }^{1,2}$ DJ College of Dental Sciences \& Research, Uttar \\ Pradesh, ${ }^{3,4}$ Buddha Institute of Dental Sciences \& Hospital, Patna, Bihar, ${ }^{5}$ Patna Medical College and Hospital, Patna, Bihar, India
}

\section{*Corresponding Author: Achla Bharti Yadav}

Email: drachlabharti@gmail.com

\begin{abstract}
Advances in molecular technologies over recent years have a profound impact on diagnostic pathology. These techniques utilize DNA, RNA and enzymes that interact with nucleic acids to understand biology at a molecular level. They will also provide a complementary approach to traditional methods of histopathological analysis in the future. Various molecular techniques are now being widely used throughout the world including polymerase chain reaction (PCR), hybridization methods, flow cytometry, tissue microarray and laser capture microdissection (LCM). Among these PCR is one of the most common diagnostic modality with high specificity, sensitivity and variety of applications. It will significantly impact three major areas: specific diagnosis, prognosis determination and prediction of response to therapy. Therefore, it has a great potential to become a standard procedure in diagnostic surgical pathology. The application of PCR in the context of dentistry is also presented here, along with the basics of PCR and its fundamental aspects.
\end{abstract}

Keywords: Applications, Dentistry, Inhibitors, Oral cancer, Polymerase Chain reaction, Tumor biology.

\section{Introduction}

Recent advances in molecular and genetic biology have revolutionized the study of DNA, RNA, and proteins, obtained from various diagnostic specimens to elucidate the complex mechanisms involved in the pathogenesis of diseases. ${ }^{1,2}$ In the field of oral and maxillofacial biology and medicine, study at the molecular level is essential for the diagnosis, prognosis, and treatment of diseases, as well as for understanding the development of normal and abnormal tissues/organs. ${ }^{3}$ The development of PCR, an acronym for Polymerase Chain Reaction is one of the most substantial technical advances in the field of molecular genetics for the in vitro amplification of DNA. ${ }^{4}$ In PCR, nucleic acid primers are hybridized to a target nucleic acid sequence to allow the enzymatic copying and subsequent amplification of the sequence of interest. ${ }^{5}$ The discoverer of the technique Dr. Kary Mullis, said "lets you pick the piece of DNA you're interested in and have as much of it as you want". 4 The present paper is an attempt to review the basics and fundamental aspects of PCR along with the applications, particularly in the context of oral pathology.

\section{Review}

\section{Historical background}

PCR was thought to be conceived by Dr. Kary Mullis in 1983 while working at the Cetus Corporation in Emeryville, CA. However, some pioneering work was also done by Gobind Khurana in 1971 who described a basic principle of replicating a piece of DNA using two primers. ${ }^{6,7}$ In 1993Kary Mullis was awarded the Nobel Prize for the discovery of PCR. In Mullis's original PCR process, the enzyme DNA polymerase extracted from the bacterium E. coli was used which gets destroy at high temperature and the enzyme had to be replenished after the heating stage of each cycle. Mullis's original PCR process was proved to be inefficient since it required a great deal of time, vast amounts of DNA-Polymerase enzyme and continual attention throughout the PCR process. ${ }^{7,8}$ The milestone in the field of molecular research and creditable for universal adoption of PCR was the isolation of a heat stable (up to $95^{\circ} \mathrm{C}$ ) enzyme Taq polymerase from extreme thermopile bacterium 'Thermus aquaticus' (1989). ${ }^{7-9}$ David Gelfand and his associates at Cetus, purified and subsequently cloned this polymerase, allowing a complete PCR amplification to be done without opening the reaction tube. ${ }^{7}$ The discovery of Taq polymerase has facilitated the development of automated PCR machines which takes about five minutes for each cycle and is programmed to control the repetitive stages of heating and cooling. .,9 $^{-1}$

\section{Reaction mixture}

Amplification of DNA requires following main components: ${ }^{4,8-10}$

1. DNA template, or cDNA which contains the region of the DNA fragment to be amplified;

2. Enzyme Taq polymerase (DNA polymerase) which copies the region to be amplified;

3. Pair of oligonucleotides that may serve as primers for DNA synthesis, that are complementary to the beginning and end of the DNA fragment to be amplified;

4. Equimolar concentrations of the four deoxynucleotide triphosphates (dATP, dCTP, dGTP, dTTP) with which to construct the new DNA strands;

5. Appropriate buffer containing $\mathrm{MgCl}_{2}$ to optimize DNA polymerase activity.

\section{Principle of $\mathbf{P C R}^{4,8-13}$}

PCR is an in vitro enzymatic amplification of a specific DNA sequence to obtain large number of DNA copies by means of an exponential rate. It is composed of the following major stages:

A. Denaturation: The double-stranded DNA (ds-DNA) is isolated from the material under study (target DNA) 
and added to the reaction mixture which contains nucleotides, primers and polymerase enzyme. This DNA is subjected to increase in temperature $\left(95-98^{\circ} \mathrm{C}\right)$ for 60 seconds for the production of two single strands of DNA (ss-DNA) which further serve as templates for the attachment of synthetic primers.

B. Annealing: Here, the temperature is reduced to approximately $37-50^{\circ} \mathrm{C}$ for $60-120$ seconds and primers (synthetic oligonucleotides, consisting of nucleotide bases pairs long which closely resembles gene of interest) are added to the reaction mixture in excess. The reduction in temperature allows the primers to bind to their complementary ss-DNA sequences (templates), one to each of the two single strands of template produced in the previous step.
C. Extension: Final step, where a thermostable DNApolymerase enzyme was added to synthesize a complimentary copy of the initial single strands by extension of the $3^{\prime}$ (but not 5') ends of the annealed primers. This is the end of the first cycle of the procedure carried out at $72^{\circ} \mathrm{C}$ for $60-120$ seconds, by which two double strands of DNA have been formed, i.e. doubling of the original target DNA molecules has been achieved.

D. Exponential amplification: This process continues exponentially as in the second cycle these 2 ds- DNA act as templates to yield four ss-DNA and the cycle repeated many number of times till the sufficient amount of DNA product is generated (target DNA) (Fig. 1).

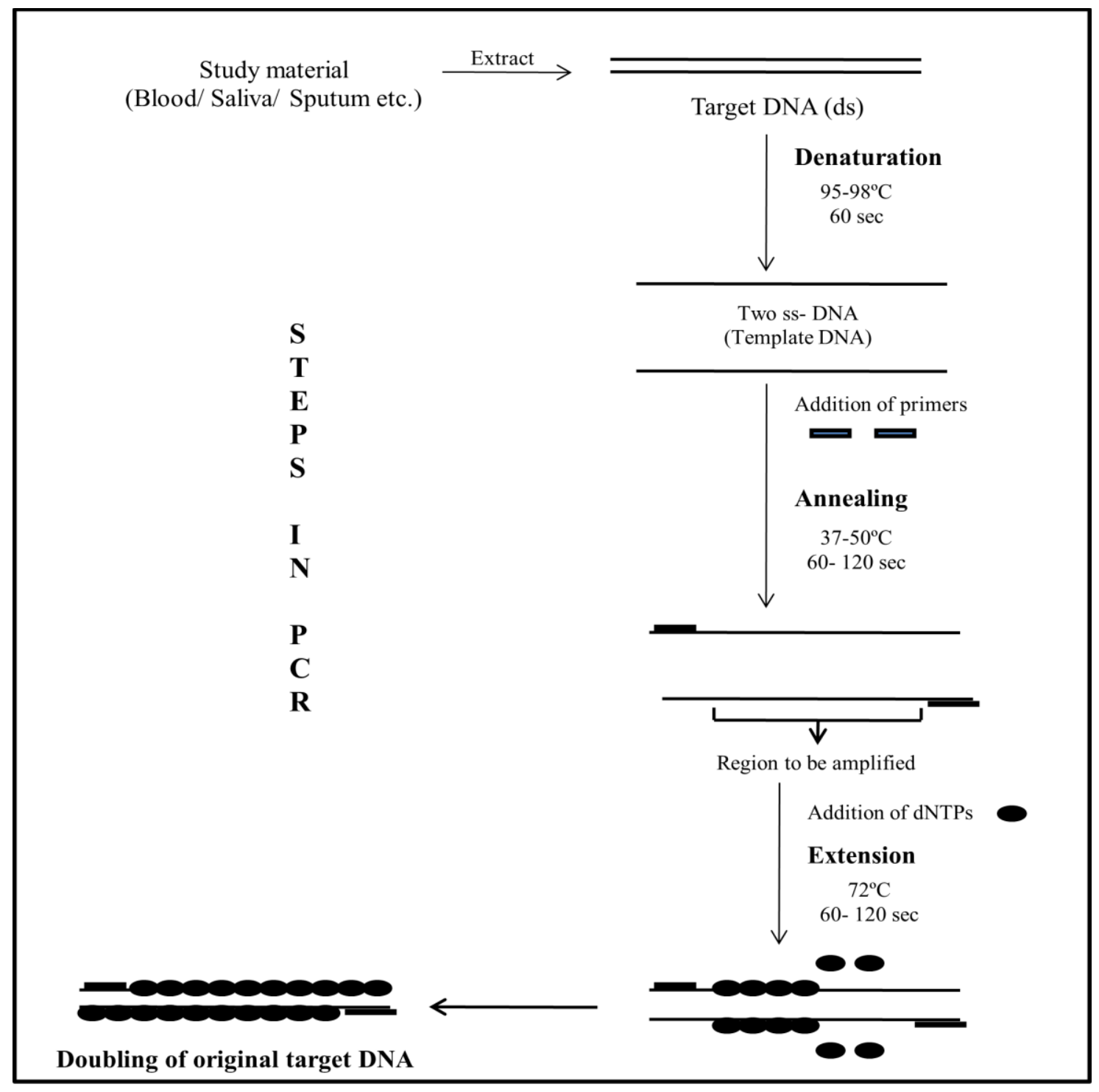

Fig. 1: Different steps in PCR 
After amplification, the PCR product can be identified by its size using an agarose or polyacrylamide gel electrophoresis, following which visualization can be done by staining with ethidium bromide to confirm the presence of a particular target sequence..$^{9,10,13}$

\section{Materials for analysis}

PCR amplifies specific DNA fragments from different types of clinical samples including blood, saliva, sputum, semen and human hairs. ${ }^{12,13}$ Even DNA in fixed pathological specimens, paraffin- embedded tissue sections, buccal cells from mouth washes, a single lymphoid, or ancient mummies can now be analyzed with the great success and high degree of sensitivity and specificity. ${ }^{8,12}$

\section{Critical aspects in analysis of cellular DNA content}

The routinely used tissue fixative i.e 4\% neutral buffered formalin causes cross linking and cuts in the DNA (nicking). Although proteolytic digestion of tissues produces large quantities of DNA, most is fragmented limiting the size of the target area of the gene that is subjected to PCR. In contrast precipitating fixatives such as ethanol and acetone do not cross- link or shear the DNA and, therefore, produce more consistent PCR results. Longer fixation times (>24 hours) may also adversely affect the quality of the DNA extracted from routinely processed tissues and thereby reduce PCR efficiency. ${ }^{14,15}$ The counter stain used for tissue visualization before DNA extraction can also affect the quality of the reaction. For example, a recent study found that PCR efficiency was highest when methyl green and neutral fast red counter stains were used, comparable to that of unstained sections. By contrast hematoxylin often produces significantly poorer PCR results, the basis for which is uncertain but possibly related to its binding to DNA phosphate groups and increased resistance towards protease digestion. ${ }^{16}$

\section{PCR inhibitors}

Since the discovery of PCR, PCR inhibitors have been an obstacle to its success. Any field which utilizes this technique impacted by inhibitors at some step of cycling process. PCR inhibitors generally exert their effects through direct interaction with DNA (prevent amplification) or interference with thermostable DNA polymerases (block enzyme activity). DNA polymerases have cofactor $(\mathrm{Mg} 2+)$ requirement, and agents that reduce $\mathrm{Mg} 2+$ availability or interfere with binding of $\mathrm{Mg} 2+$ to the DNA polymerase can inhibit PCR. Common sample types known to contain inhibitors include blood, fabrics, tissues and soil. In blood, serum or plasma samples, substances like $\mathrm{IgG}$, haemoglobin and lactoferrin have been described as inhibitors of PCR. Anticoagulants, for example, heparin, may also inhibit the PCR. The most critical component in urine samples is urea, which may lead to the degradation of the polymerase. Other important sources of inhibitors are the materials and reagents that come into contact with samples during processing or DNA purification. These include excess $\mathrm{KCl}$, $\mathrm{NaCl}$ and other salts, ionic detergents such as sodium deoxycholate, ethanol and isopropanol, phenol and others. DNA purification is the method used most often to remove inhibitors. ${ }^{17,18}$

\section{Applications of PCR technique ${ }^{8,9,19,20}$}

Application of PCR has been extended to a wide variety of biological and medical disciplines; fields of application include molecular genetics, evolutionary biology, pathology, microbiology tumor biology, forensic medicine and dentistry.

A. Human genetics: The ability to amplify specific DNA sequences by the PCR has made possible the rapid and accurate diagnosis of many inheritable diseases. The initial diagnostic application of the PCR was in the prenatal diagnosis of sickle cell anemia through application of $\beta$-globulin sequences (1985). This has served as a model system for the detection of genetic mutations in the range of disorders, e.g. $\beta$-thalassaemia, hemophilia, gaucher's disease, phenylketonuria and cystic fibrosis. Also, the PCR can be used for the study of genetic predisposition of autoimmunity and identification of oncogenes and tumor suppressor genes in cancer and human leukocyte antigen (HLA) typing. It also analyzes fetal DNA for aneuploidy (the presence of extra chromosomes or the absence of chromosomes), trisomy 21, Turner's syndrome, Klinefelter's syndrome, and for sex determination.

B. Evolution science: The PCR analysis of specimens from archeological material and museum collections is proving to be of great assistance in assessing the past and present genetic makeup of extinct and endangered animal populations. Samples from the skin of stuffed specimens were subjected to the PCR and subsequent analysis of the amplified DNA revealed the 'quagga' to be a variant of the zebra and not a distinct species.

C. Detection of pathogenic microorganisms: The detection of viruses associated with several cancers such as Burkitt's Lymphoma, adult T- cell leukemia and cervical carcinoma provides valuable information on diagnosis and prognosis. The PCR can be of tremendous value in the detection of latent viral infections which persist for several weeks or years, without manifesting the disease, e.g. Hepatitis $\mathrm{B}$ and Hepatitis C infections, Human immunodeficiency virus1 (HIV-1) infection especially in neonates. Examples of pathogenic bacteria detected by PCR are species of Mycobacterium, Vibrio, Treponema and Chlamydia from clinical specimens; Shigella, Staphylococcus and Listeria from food; and Legionella, Enterobacteria and the protozoan giardia from water. However, several problems have to be overcome in these applications like interference with the PCR by components of blood and food and the amplification of DNA from non-viable organisms in food that have been killed by pasteurization.

D. Environmental applications: Of particular interest of the application of PCR related to environment are the possibility of detecting bacteria that cannot be cultured 
and the monitoring of the distribution of genetically engineered microorganisms that have been released to the environment. It may also be applied in the further enhancement of existing rapid procedures for monitoring water quality by the detection of coliform bacteria and Escherichia coli, the specific indicator of human faucal contamination.

E. Tumor biology: PCR has been used to detect mutations in cancer associated oncogenes (eg. K-ras, N-ras), tumor suppressor genes (eg. p53, p16), monoclonality in B- and T-cell lymphomas, chromosomal translocations such as the Philadelphia chromosome $\mathrm{t}(14 ; 18)$ in chronic myelogenous leukemia, and minimal residual neoplastic disease.

F. Forensic pathology: PCR has been used in a range of situations, including for the identification of mutilated or decomposed human tissues, for sex determination, and for disputed paternity cases. "DNA fingerprinting" is based on the identification of variable tandem repeats, short, repeating DNA nucleotide sequences that litter the human genome. This process has proved to be an important tool in the identification of terminals.

G. Routine diagnostic laboratory: From the foregoing examples of applications, it should be apparent that the PCR technique is more suited to use in research than in the busy routine diagnostic laboratory. However, once an exotic tool of the research scientists, PCR has its full potential only if made accessible to the clinical laboratory as it improves the accuracy and speed for the diagnosis of infectious diseases, inherited disorders and tissue matching.

\section{PCR: Pertinency to Dentistry}

Literature suggests the use of PCR for the study of factors involved in periodontal diseases, dental caries, endodontic infections and oral cancer. ${ }^{13,19,21}$

\section{Periodontal diseases ${ }^{13,21-27}$}

In the search of the possible involvement of human viruses in periodontal diseases using PCR technique; Parra and Slots determined the prevalence of Human Cytomegalovirus (HCMV), Epstein-Barr Virus Type I and II (EBV 1 and 2), Herpes Simples Virus (HSV), Human Papillomavirus (HPV) and Human Immunodeficiency Virus (HIV) in the crevicular fluid of individuals with various forms of periodontal disease. Ssygun et al confirmed the frequent presence of HCMV in crevicular samples of chronic periodontal lesions and suggested a strong relation between HCMV and EBV-1 in subgingival areas with deep furrows. Studies have detected Actinobacillus actinomycetemcomitans in a population with $(70 \%)$ and without (19\%) periodontal disease using PCR. These studies have also shown the better sensitivity and specificity of PCR in comparison to traditional culture methods. Okada et al used PCR to detect the presence of A. actinomycetemcomitans and $\mathrm{P}$. gingivalis in dental plaque samples from children using their toothbrushes. The research indicated that such bacteria are rarely present in the oral cavity of healthy children. Sakamoto et al suggests the saliva as good sample for PCR than subgingival plaque in detection and quantification of periodontal bacteria of the oral cavity.

\section{Dental caries ${ }^{13,21,28-32}$}

The group mutans encompasses cariogenic bacteria with seven species: Streptococcus cricettus, S. ratti, S. mutans, S. sobrinus, S. downei, S. ferus and S. macacae, of which S. mutans and $\mathrm{S}$. sobrinus are more frequently isolated from the human oral cavity. The discriminative power of PCR in the differentiation of $\mathrm{S}$. mutans and S. sobrinus serotypes and lineages was investigated by Saarela et al, who found that PCR exhibited good results in differentiating S. mutans lineages and the technique is appropriate for epidemiological studies on this bacterium. Rupf et al presented a competitive PCR method for the specific quantitative determination of $\mathrm{S}$. mutans. This method allowed a quick, exact determination of unknown quantities of this bacterium and provided an efficient means for evaluating the risk of caries in patients as well as monitoring the efficiency of preventative and therapeutic measures.

\section{Endodontic infections ${ }^{13,21,33-37}$}

Examples of bacterial species that were only detected in canals through molecular methods and that are currently considered important endodontic pathogens include Treponema denticola, Dialister pneumosintes, Filifactor alocis, Tannerella forsythia, Treponema malthophilum, Treponema socranskii and Prevotella tannerae. Based on current studies, molecular methods can be used to characterize the micro-flora associated to endodontic infections. Using PCR, Bogen and Slots sought to determine the prevalence of $\mathrm{P}$. endodontalis, $\mathrm{P}$. gingivalis, $\mathrm{P}$. intermédia and $\mathrm{P}$. nigrescens in patients with refractory periapical lesions. The authors concluded that bacteria that produce black pigment do not appear to constitute the majority of microorganisms in these cases. The relatively lower occurrence of these bacteria may help explain the relative stability and chronic nature of this condition. Although studies have determined that bacteria are the greatest etiological agent in pulp and periradicular disease, fungi have also been associated to root canal infection. Baumgartner et al used PCR to assess the content of infected root canals as well as cellulite aspirations and abscesses of endodontic origin for the presence of Candida albicans. The results indicate that PCR is an extremely sensitive molecular method and can be used to identify C. albicans directly in samples of endodontic infection. PCR has revolutionized medical microbiology and is broadening the horizons with regard to the actual profile of endodontic infection.

\section{Oral cancer $^{13,21,38-43}$}

One of the uses of PCR in dentistry is the detection of markers in the diagnosis and prognosis of some types of oral cancer. Pre-malignant lesions of the head and neck have been studied extensively through genetic alterations using 
PCR.41 HPV (Human Papilloma virus) has been employed in tumor progression in cancer patients. 42 Determining the moment of viral infections in premalignant lesions could clarify the role of HPV in carcinogenesis and help guide future strategies for the prevention and early detection of squamous cell carcinoma of the head and neck.

\section{Variants of $\mathrm{PCR}^{5,6,10,11}$}

Quantitative PCR (Q-PCR): It is used to measure the specific amount of target DNA (or RNA) in a sample. Special thermal cyclers are used that monitor the amount of product during the amplification. Quantitative Real-Time PCR (QRT-PCR) methods use fluorescent dyes such as Sybr Green or fluorophore-containing DNA probes such as TaqMan, to measure the amount of amplified product as the amplification progresses.

Reverse transcription PCR (RT-PCR): The analysis of mRNA is important because it provides direct evidence of cell transcription and therefore, is a measure of cellular function. Determination of mRNA is certainly difficult in tissue sections by conventional methods. The reason being that, as the whole amount of RNA itself in a cell may be as little as $2 \%$, furthermore mRNA is highly unstable with short life span. An important innovation and modification of PCR is the detection and quantification of mRNA in cells. The basis of RT- PCR is the conversion of RNA to DNA. cDNA is that which is transcribed from an RNA template by the enzyme reverse transcriptase (RT). This enzyme functions in an analogous but reverse manner to the way RNA is made from a DNA template by RNA polymerases. This cDNA can then be used as a template for PCR or quantitative PCR. If the starting material were mRNA, then the resultant cDNA would contain only exons (the parts of the gene that are found in the mRNA molecule that will be used to code for the proteins) and not introns (the part of the gene that is not found in the transcribed mRNA) because these are spliced out when mRNA is made.

An important application of RT- PCR has been in the detection and quantification of the transcripts of tumor associated translocations. For example, the Philadelphia chromosome $[t(9: 22)]$ is a genetic alteration that is most commonly identified in chronic myeloid leukemias and a subset of acute lymphoblastic leukemias. Others including $\mathrm{t}(15 ; 17)$ in acute promyelocytic leukemia, $\mathrm{t}(8 ; 14)$ in Burkitt's lymphoma, $\mathrm{t}(2 ; 5)$ in anaplastic large cell lymphoma, $\mathrm{t}(11 ; 12)$ in Ewing's sarcoma and primitive neuroectodermal tumor, and $\mathrm{t}(2 ; 13)$ in alveolar rhabdomyosarcoma. This can also be used for the post treatment detection of minimum residual disease in patients with leukemia.

Multiplex-PCR ${ }^{44}$ :It is defined as the simultaneous amplification of multiple regions of DNA templates by adding more than one primer pair to the amplification reaction mixture. Since first being described in 1988, PCR multiplexing has been applied in many areas of DNA testing including the analysis of deletions, mutations, and short tandem repeats (STRs). Furthermore, the wide availability of genetic information due to the publishing of the sequence of the human genome makes the demand for multiplex PCR even greater. For example, more than 1.4 million single nucleotide polymorphisms (SNPs) have been identified in the human genome. Multiplex PCR primer sets have been used for linkage studies to track genetic diseases. Eukaryotic genomes are full of repeated DNA sequences. These repeated sequences come in all sizes, and are designated by the length of the core repeat unit and the number of contiguous repeat units or the overall length of the repeat region. These regions are often referred to as satellite DNA. DNA regions with repeat units that are 2-6 bp in length are called microsatellites or short tandem repeats (STRs) and can be readily amplified with PCR.

Nested PCR: It is used to increase the specificity of DNA amplification. Two sets of primers are used in two successive reactions. In the first PCR, one pair of primer is used to generate DNA products, which may contain products amplified from non-target areas. The products from the first PCR are then used as template in a second PCR, using one ('hemi-nesting') or two different primers whose binding sites are located (nested) within the first set, thus increasing specificity. Nested PCR is often more successful in specifically amplifying long DNA products than conventional PCR, but it requires more detailed knowledge of the sequence of the target.

Hot-start PCR: It is a technique performed manually by heating the reaction components to the DNA melting temperature (e.g. $95^{\circ} \mathrm{C}$ ) before adding the polymerase. In this way, non-specific amplification at lower temperatures is prevented. Alternatively, specialized reagents inhibit the polymerase's activity at ambient temperature, either by the binding of an antibody, or by the presence of covalently bound inhibitors that only dissociate after a hightemperature activation step.

Future: The PCR is undergoing continual transformations since it has been discovered; to overcome technical difficulties encountered during the processing. Furthermore, necessary modifications and refinements of the PCR are continued at a rapid pace. For example, two new polymerases: Thermococcuslitoralis (VENT polymerase) and Pyrococcusfuriosus have been discovered which are extreme thermopiles and have advantage in specificity over Taq polymerase. ${ }^{9}$

\section{Conclusion}

PCR technique is currently revolutionizing the practice of surgical pathology; favoring the early recognition of disease and optimized treatment thus increasing the sensitivity, precision and accuracy of diagnosis. Recently, it has become a standard diagnostic and research tool in various fields including dentistry. Such molecular techniques begin a new era in diagnostic inevitability.

\section{Source of funding}

None.

\section{Conflict of interest}

None. 


\section{References}

1. Sheils O, Smyth P, O’Regan E, Finn S, Flavin R, O’Leary J. Laser capture microdissection. In: Burnett D, Crocker J. The science of laboratory diagnosis, 2nd ed. John Wiley and sons Ltd. England; 2005. p. 489.

2. Jordan RCK, Daniels TE, Greenspan JS, Regezi JA. Advanced diagnostic methods in oral and maxillofacial pathology. Part I: Molecular methods. Oral Surg Oral Med Oral Pathol Oral Radiol Endod 2001;92(6):650-69.

3. Ida K, Nishimura I. Gene expression profiling by DNA microarray technology. Crit Rev Oral Biol Med 2002;13(1):3550.

4. Mullis K. The unusual origin of the polymerase chain reaction. Sci Am 1990;262:56-65.

5. Jones ML. Molecular pathology and in situ hybridization. In: Bancroft JD, Gamble M. Theory and practice of histological techniques. 5th ed. Churchill Livingstone Elsevier; 2002. p. 553.

6. Nolan T, Bustin SA. PCR Technology: Current innovations. 3rd ed. CRC press, taylor and francis group; 2013.

7. Methods in Molecular Biology, Vol 226. In: Bartlett JMS, Stirling D. PCR Protocols. 2nd ed. Humana Press Inc., Totowa, NJ; 2002.

8. Eisenstein BI. The polymerase chain reaction - A new method of using molecular genetics for medical diagnosis. $N$ Engl $J$ Med 1990;322:178-83.

9. Giasuddin ASM. Polymerase chain reaction technique: fundamental aspects and applications in clinical diagnostics. $J$ Islam Acad Sci 1995;8:29-32.

10. Rahman MT, Uddin MS, Sultana R, Moue A, Setu M. Polymerase chain reaction (PCR): A short review. J Anwer Khan Modern Med Coll 2013;4:30-6.

11. Mhaske S, Yuwanati M. Advanced diagnostic techniques. In: Ghom AG, Mhaske S. Textbook of Oral Pathology. 2nd ed. Jaypee Brothers Medical Publishers; 2013; p. 61-2.

12. Joshi M, Deshpande JD. Polymerase chain reaction: methods, principles and application. Int J Biomed Res 2010;1:81-97.

13. Santos CF, Sakai VT, Machado MA, Schippers DN, Greene AS. Reverse transcription and polymerase chain reaction: principles and applications in dentistry. J Appl Oral Sci 2004;12(1):1-11.

14. Srinivasan M, Sedmak D, Jewell S. Effect of fixatives and tissue processing on the content and integrity of nucleic acids. Am J Pathol 2002;161(6):1961-71

15. Hunt JL. Molecular pathology in anatomic pathology practice: A review of basic principles. Arch Pathol Lab Med 2008;132(2):248-60.

16. Burton MP, Schneider BG, Brown R, Escamilla-Ponce $\mathrm{N}$, Gulley ML. Comparison of histologic stains for use in PCR analysis of microdissected, paraffin-embedded tissues. Biotechniques 1998;24(1):86-92

17. Schrader C, Schielke A, Ellerbroek L, Johne R. PCR inhibitors - occurrence, properties and removal. J Appl Microbiol 2012;113(5):1014-26

18. Bessetti J. An introduction to PCR inhibitors. Profiles in DNA 2007;10:9-10

19. Ficarra G, Eversole LR. Polymerase chain reaction: relevance for oral pathology. Minerva Stomatol 1992;41(10):425-9.

20. Netto GJ, Saad RD, Dysert PA. Diagnostic molecular pathology: current techniques and clinical applications, part I. BUMC Proceedings 2003;16:379-83.

21. Valones MAA, Guimarães RL, Brandão LAC, Souza PRE, Tavares AA, Crovela S. Principles and applications of polymerase chain reaction in medical diagnostic fields: a review. Braz J Microbiol 2009;40:1-11.

22. Parra B, Slots J. Detection of human viruses in periodontal pockets using polymerase chain reaction. Oral Microbiol Immunol 1996;11(5):289-93.
23. Saygun I, Sahin S, Ozdemir A, Kurtis B, Yapar M, Kubar A et al. Detection of human viruses in patients with chronic periodontitis and the relationship between viruses and clinical parameters. J Periodontol 2002;73(12):1437-43.

24. Mullally BH, Dace B, Shelburne CE, Wolff LF, Coulter WA. Prevalence of periodontal pathogens in localized and generalized forms of early-onset periodontitis. $J$ Periodont Res 2000;35(4):232-41.

25. Tran SD, Rudney JD. Improved multiplex PCR using conserved and species-specific 16S rRNA gene primer for simultaneous detection. J Clin Microbiol 1999;37(11):3504-8.

26. Okada M, Hayashi F, Nagasaka N. Detection of Actinobacillus actinomicetemcomitans and Porphyromonas gingivalis in dental plaque samples from children 2 to 12 years of age. $J$ Clin Periodontol 2000;27(10):763-8.

27. Sakamoto M, Takeuchi Y, Umeda M, Ishikawa I, Benno Y. Rapid deteccion and quantification of live periodontopathic bacteria by real time PCR. Microbiol Immunol 2001;45(1):3944.

28. Hirasawa M, Takada K. A new selective medium for Streptococcus mutans and the distribution of S. mutans and S. sobrinus and their serotypes in dental plaque. Caries Res 2003;37(2):212-7.

29. Whiley RA., Beighton D. Current classification of the oral streptococci. Oral Microbiol Immunol 1998;13(4):195-216.

30. Yoo SY, Kim PS, Hwang HK, Lim SH, Kim KW, Choe SJ et al. Identification of non-mutans streptococci organisms in dental plaques recovering on mitis salivarius bacitracin agar medium. J Microbiol 2005;43(2):204-8.

31. Saarela M, Hannula J, Matto J, Asikainen S, Alaluusua S. Typing of mutans streptococci by arbitrarily primed polymerase chain reaction. Arch Oral Biol 1996;41(8-9):821-6.

32. Rupf S, Kneist S, Merte K, Eschrich K. Quantitative determination of Streptococcus mutans by using competitive polymerase chain reaction. Eur J Oral Sci 1999;107(2):75-81.

33. Siqueira JF, Rôças IN. PCR methodology as a valuable tool for identification of endodontic pathogens. J Dent 2003;31(5):3339.

34. Kim Y, Flynn TR, Donoff RB, Wong DTW, Tood R. The gene: the polymerase chain reaction and its clinical application J Oral Maxillofac Surg 2002;60(7):808-15.

35. Bogen G, Slots J. Black-pigmented anaerobic rods in closed periapical lesions. Int Endod J 1999;32(3):204-10.

36. Baumgartner JC, Watts CM, Xia T. Occurrence of Candida albicans in infections of endodontic origin. $J$ Endod 2000;26(12):695-8

37. Siqueira Jr JF, Rôças IN. A 16 rDNA-based nested PCR protocol to detect Campylobacte gracilis in oral infections. Pesqui Odontol Bras 2003;17(2):142-6.

38. Kariyazono H, Ohno T, Ihara K, Igareshi H, Joh OK, Ishikawa $\mathrm{S}$ et al. Rapid detection of the 22q 11.2 deletion with quantitative real-time PCR. Mol Cell Probes 2001;15(2):71-3.

39. Lee BK, Diebel E, Neukam FW, Wiltfang J, Ries J. Diagnostic and prognostic relevance of expression of human telomerase subunits in oral cancer. Int J Oncol 2001;19(5):1063-8.

40. Reis PP, Rogatto SR, Kowalski LP, Nishimoto IN, Montovani SC, Corpus G et al. Quantitative real-time PCR identifies a critical region of deletion on 22q13 related to prognosis in oral cancer. Oncogene 2002;21(42):6480-7.

41. Califano J, Riet VDP, Westra W, Nawroz H, Clayman G, Piantadose $\mathrm{S}$ et al. Genetic progression model for head and neck cancer: implications for field cancerization. Cancer Res 1996;56(11):2488-92.

42. Gillison ML, Koch WM, Capone RB, Spafford M, Westra $\mathrm{WH}, \mathrm{Wu} \mathrm{L}$ et al. Evidence for a causal association between human papillomavirus and a subset of head and neck cancers. $J$ Natl Cancer Inst 2000;92(9):709-20. 
43. Ha PK, Pai SI, Westra WH, Gillison ML, Tong BC, Sidransky $\mathrm{D}$ et al. Real-time quantitative PCR demonstrates low prevalence of human papillomavirus type 16 in premalignant and malignant lesions of the oral cavity. Clin Cancer Res 2002;8(5):1203-9.

44. Edwards MC, Gibbs RA. Multiplex PCR: advantages, developments and applications. Genome Res 1994;3:S65-75.

45. Markham AF. The polymerase chain reaction: a tool for molecular medicine. Br Med J 1993;306:441-6.

46. Persing DH. Polymerase chain reaction: trenches to benches. $J$ Clin Microbiol 1991;29:1281-5.

47. Roux KH. Optimization and troubleshooting in PCR. Genome Res 1995;4:S185-94.

48. Chien A, Edgar DB, Trela JM. Deoxyribonucleic acid polymerase from the extremethermophile Thermusaquaticus. $J$ Bacteriol 1976;127:1550-7.

How to cite this article: Yadav SK, Yadav AB, Kedia NB, Kedia G, Kumar K. Polymerase chain reaction (PCR) - A review with its pertinency to dentistry. Int J Oral Health Dent 2019;5(4):184-90. 